\title{
Model Predictive Control for load frequency stabilizer
}

\author{
H. A. Ahmed, A. M. Rashwan, A. M. Abdel-Moamen \\ Department of Electrical Engineering, Faculty of Energy Engineering, Aswan University \\ 81528, Aswan, Egypt
}

\begin{abstract}
:
This paper deals with the importance of load frequency control (LFC) for single and interconnected power system. It is important to keep the frequency of the system and the inter area tie power stable. The goal of LFC is to maintain the frequency, the desired power output and to control the change in tie line power between control areas in an interconnected power system. Two different techniques have been implemented in this paper which are model predictive controller MPC and conventional proportional plus integral controller PI for LFC of single area power system as well as two area system. To investigate the powerful and robustness of model predictive control (MPC) technique for LFC problems in electric power system, time simulations is performed. The obtained results indicate that the MPC provide better damping to the single area system as well as two-area system in case of load disturbance compared with conventional PI controller. The studied single-area and two-area systems are modelled and simulated using Simulink/Matlab software.

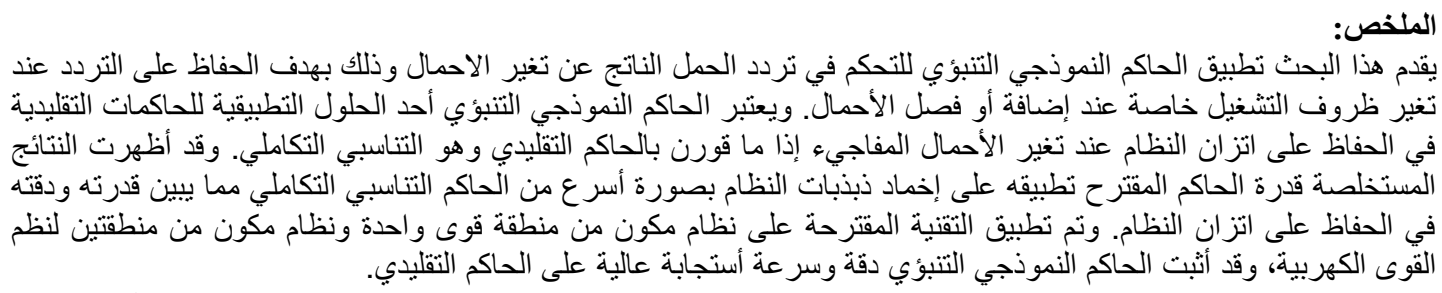

Keywords: Load frequency control; Model predictive control; single area power system; two area power system.

\section{Introduction:}

Load frequency control is one of the important ancillary services in the deregulated power scenario. It is an essential mechanism in power system design, operation and control to satisfy the objectives of LFC. Under deregulated environment the existing power system model has been reconfigured in a manner that it enables the emerging of separate utility for generation, transmission, distribution and an independent system operator [1].

The control of power system can be separated into two independent problems according to the two main principle variables which are the voltage and the frequency because all the other variables are dependent on them .The changes in active power affect directly the system frequency and the changes in voltage magnitude affect the reactive power and that is why it is controlled separately. The active power and frequency control is called load frequency control (LFC) and the automatic voltage regulator (AVR) loop regulates the reactive power and voltage magnitude [2]. The frequency of a power system is depending on the speed at which the generators are rotated by their prime movers. So, frequency control is basically a matter of speed control of the machines in the generating station [3]. The proportional, integral pulse derivative (PID) parameters of the PID controllers applied to multi-area power system successfully for damping frequency oscillation in case of small disturbance as well as large scale disturbance. A (PID) optimized by the lozi map-based chaotic algorithm (LCOA) is used to solve the load frequency control (LFC) problems. The PIDs tuned by (LCOA) is used in each area [4]. PI controller designed based on (LFC) in multi-area power system has been formulated as a robust optimization control problem. The kharitonov's theorem is used to determine the margin which is optimized and other parameters to achieve the optimum (PI) controller parameters [5].For a large interconnected power system another technique of control is applied to tune parameters of (PI) controller of each area of multi-area power system for LFC. The system intended is consisting of conventional and renewable energy source [6]. Firefly algorithm (FA) is applied to optimize fuzzy PID controller with derivative filter (PIDF) for (LFC) of multi-area source system under de regulated environment such as GRC and GDB non-linearity. Genetic algorithm (GA) is used for comparing the results to achieve the purpose [7]. A numerical method is presented to solve the non-linear system 
when a disturbance occurs [8]. Also, the principle of nonlinear programming is applied to the system to optimize the performance of a power system subject to (LFC) [9]. The Ho controller is used alone to solve the (LFC) problem, or based on laypunov stability theory [10-11]. Another load frequency controller design has been applied for power system steam turbine which is based on the polynomial $\mathrm{H} \infty$ robust control theory [12]. For the hybrid power system, sliding mode load frequency control is designed to reduce frequency deviation. To improve the performance and suppress the chattering, the controller is reconstructed based on the design disturbance observer (DOB) [13]. Model predictive control (MPC) is a model based process control technology that has been successfully employed in industrial settings; a description of some industrial MPC packages in existence during the last decades, and the features that reconcile them with important industrial process control issues are available. Within the context of power system, MPC has been applied to control the boiler system of a fossil-fired power station, coordinated control of voltage in power networks, dynamic load balancing of a power system portfolio and wind turbine applications and its coordination with plug-in electric vehicles.

Model predictive control (MPC) technique of load frequency control can be used alone as an independent controller without any other controller or with another controller in an interconnected power system [14-15]. Distributed model predictive controller (DMPC) technique for (LFC) is designed for the multi-area power system and considered one of many techniques to achieve the proposed aim. So that, (DMPC) algorithm has been applied for each area because each area owns its (MPC) controller. Model predictive controller is used for islanded AC micro grids and in that case it is based on hierarchical control scheme which is applied to address power quality and unequal power sharing problems. Also it can used for AC frequency containment [16-17]. Also it is used for electrical heating systems [18]. It is used for building loads connected with residential distribution grid [19].

This paper addresses the effectiveness of the model predictive control MPC technique for load frequency stabilization of single area system and two- area system. Different level of loads are suggested to examine the performance of the MPC in damping the frequency oscillations due to load change. The simulation results proves the superiority of the MPC technique over the conventional PI technique for both single area and two-area power systems.

\section{Studied System Model}

The Single-Area power system is as shown in Fig. 1 [20]. The two-area power system model is as shown in Fig. 2.

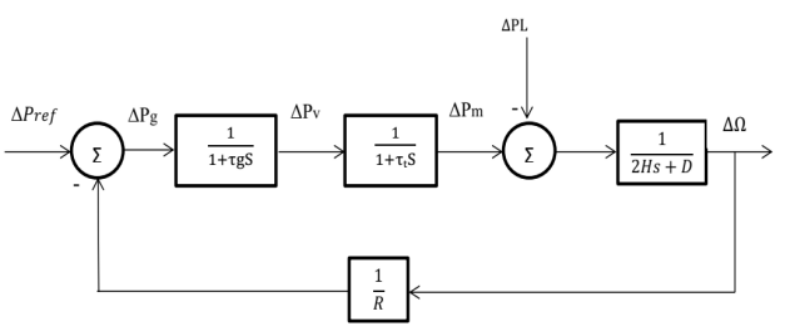

Fig. 1. Block Diagram of Single-Area Power System

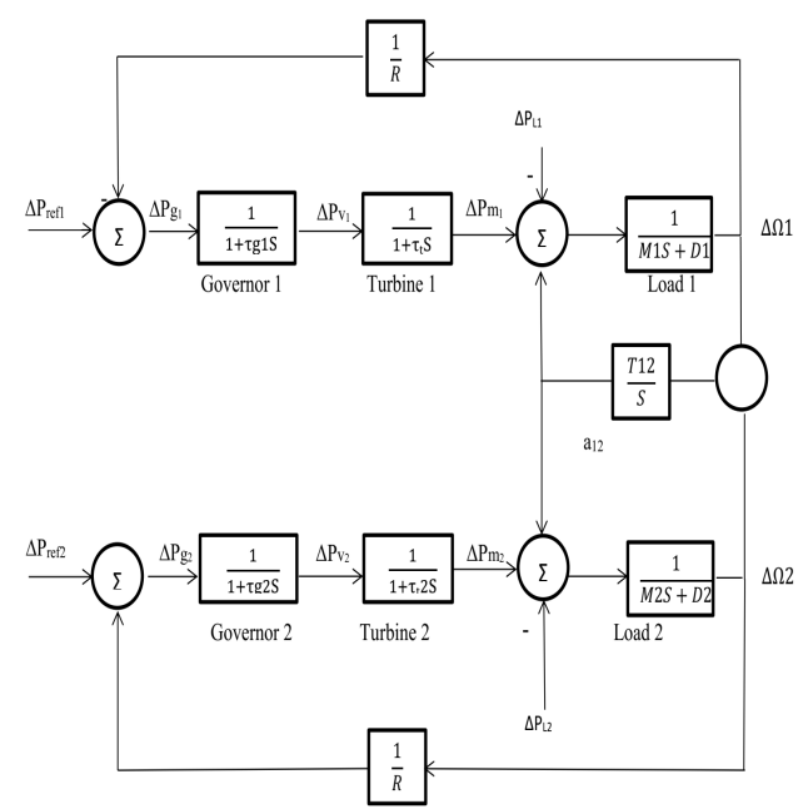

Fig. 2. Block Diagram of Two -Area Power System

\section{Model Predictive Control (MPC) Technique}

MPC schemes use linear models of the controlled system to predict the system dynamics with consideration of linear constraints on the system states and inputs and optimize the control actions accordingly. In another meaning, the MPC is based on the prediction of the system; the (MPC) scheme is based on an explicit use of a prediction model of the system response to obtain the control actions by minimizing an objective function [21-24]. Internal past and current values of the inputs and outputs and the proposed optimal future control actions are considered in the MPC response. The prediction has two main components: the free response which is expected behavior of the output assuming zero future control actions, and the forced response which is the additional component of the output response due to the candidate set of future controls. For a linear systems, the total prediction can be calculated by summing both of free and forced responses. The optimizer is used to calculate the best set of future control action by minimizing a cost function ( $\mathrm{J}$ ). The optimization is subject to constraints on both manipulated and controlled variables Fig. 3 shows a simple structure of the MPC controller [22]. 


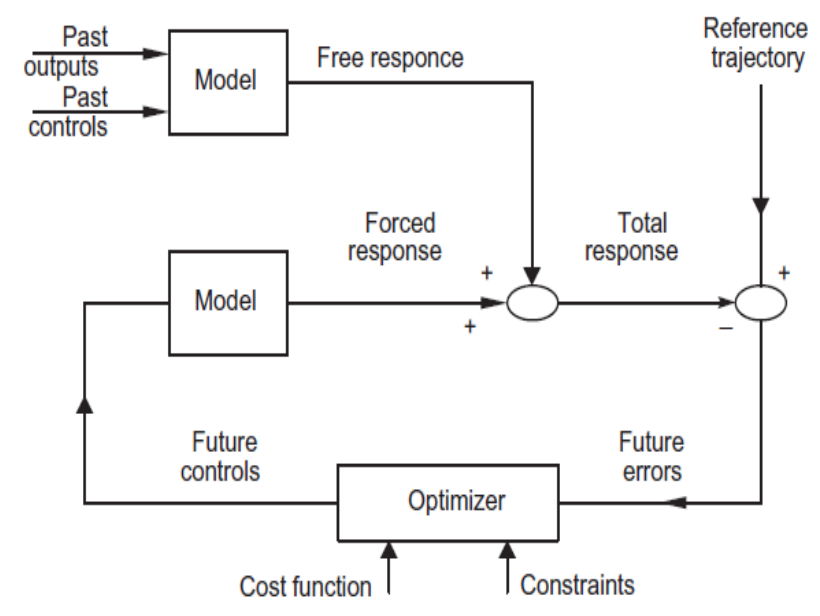

Fig. 3 A simple structure of the MPC controller [22]

The general objective is to tighten the future output error to zero, with a minimum input effort. The cost function to be minimized is generally a weighted sum of square predicted errors and square future control values, e.g. in the Generalized Predictive Control (GPC)[15]:

$j\left(N_{l}, N_{2}, N_{u}\right)=\sum_{j=N_{1}}^{N_{2}} \alpha(j)[y(k+j)-w(K+j)]^{2}+\sum_{j=1}^{N_{u}} \beta(j)$ $[\Delta u(k+j-1)]^{2}$

Where $\mathrm{N}_{1}, \mathrm{~N}_{2}$ are the lower and upper prediction horizons over the output, $\mathrm{Nu}$ is the control horizon, $\alpha(\mathrm{j}), \beta(\mathrm{j})$ are weighting factors. The control horizon permits to decrease the number of calculated future control according to the relation: $\Delta \mathrm{u}(\mathrm{k}+\mathrm{j})$ for $\mathrm{J} \geq \mathrm{Nu}$. The $\mathrm{w}(\mathrm{k}+\mathrm{j})$ represents the reference trajectory over the future horizon N. Constraints over the control signal, the outputs and the control signal changing can be added to the cost function as follows[15]:

$u_{\min } \leq(k) \leq u_{\max }$

$\Delta u_{\min } \leq \Delta(k) \leq \Delta u_{\max }$

$y_{\min } \leq(k) \leq y_{\max }$

Where:

$\mathrm{y}(k+j)$ is the predicted output

$N_{\mathrm{u}}$ is the control horizon

$\Delta \mathrm{u}$ is the controlled input increment

$\mathrm{u}$ is the controlled input

Solution of Eq. (1) gives the optimal sequence of control signal over the horizon $\mathrm{N}$ while respecting the given constraints of Eqns.(2-4).

\section{Results and Discussions}

The Data for the single-area power system, and two-area power system is as shown in Table 1 , and Table 2 respectively.
Table (1) Parameters and data for single and two-area power systems.

\begin{tabular}{|l|l|l|l|l|l|l|}
\hline Area & $\mathrm{K}(\mathrm{s})$ & $\mathrm{D}(\mathrm{p} . \mathrm{u} / \mathrm{Hz})$ & $2 \mathrm{H}(\mathrm{pu} \mathrm{s})$ & $\mathrm{R}(\mathrm{Hz} / \mathrm{pu})$ & $\mathrm{Tg}(\mathrm{s})$ & $\mathrm{T}(\mathrm{s})$ \\
\hline Area 1 & $-0.3 / \mathrm{s}$ & 0.015 & 0.1667 & 3.00 & 0.08 & 0.4 \\
\hline Area 2 & $-0.2 / \mathrm{s}$ & 0.016 & 0.2017 & 2.73 & 0.44 & 0.2 \\
\hline
\end{tabular}

Table (2) Parameters and data a practical two area power system.

\begin{tabular}{|c|c|l|l|l|l|l|}
\hline Area & $\mathrm{K}(\mathrm{s})$ & $\mathrm{D}(\mathrm{pu} / \mathrm{Hz})$ & $2 \mathrm{H}(\mathrm{pu} \mathrm{s})$ & $\mathrm{R}(\mathrm{Hz} / \mathrm{pu})$ & $\mathrm{T}_{\mathrm{g}}(\mathrm{s})$ & $\mathrm{T}(\mathrm{s})$ \\
\hline Area 1 & $-0.3 / \mathrm{s}$ & 0.015 & 0.1667 & 3.00 & 0.08 & 0.4 \\
\hline Area 2 & $-0.2 / \mathrm{s}$ & 0.016 & 0.2017 & 2.73 & 0.44 & 0.2 \\
\hline
\end{tabular}

The simulation studies are carried out for the proposed controller with generation rate constraint (GRC) of $10 \% \mathrm{pu}$ per minute. The maximum value of dead band for governor is specified as $0.05 \%$. The parameters of the MPC controller is[25]:

Prediction horizon $=10$,

Control horizon $=2$,

Weights on manipulated variables $=0$,

Weights on manipulated variables rates $=0.1$,

Weights on the output signals $=1$, and

Sampling interval $=0.06 \mathrm{~s}$.

Constraints are imposed over the control action, and frequency deviation are considered as follows:

Max. control action $=0.25$ pu.

Min. control action $=-0.25 \mathrm{pu}$.

Max frequency deviation $=0.25 \mathrm{pu}$.

Min. frequency deviation $=-0.25 \mathrm{pu}$.

Figs. 4, 5, 6, and 7 depict frequency deviation response with MPC against PI controller of single area for $\Delta P_{L}=0.005$, $0.01,0.015,0.02$ pu respectively. From the simulation results it is clear that, the MPC controller, provides better and fast response in damping the frequency oscillations when it is compared with the considered PI controller.

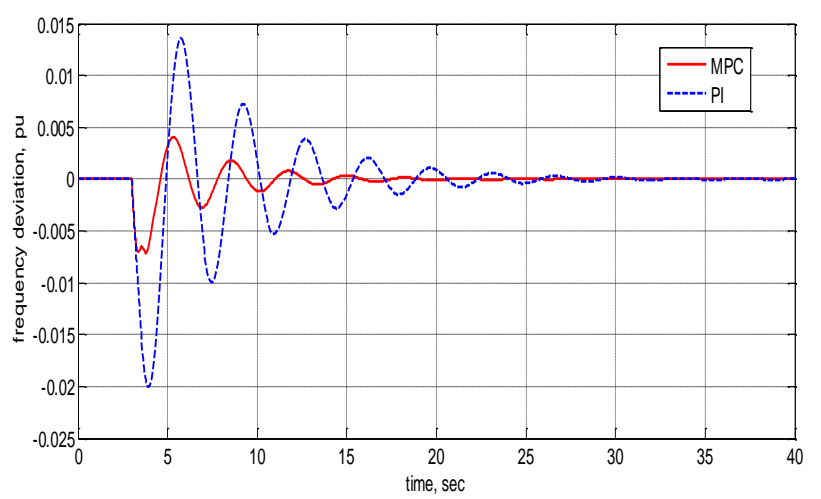

Fig. 4 The frequency response of the studied system due to step change of 0.005 in $\Delta \mathrm{P}_{\mathrm{L}}$. 


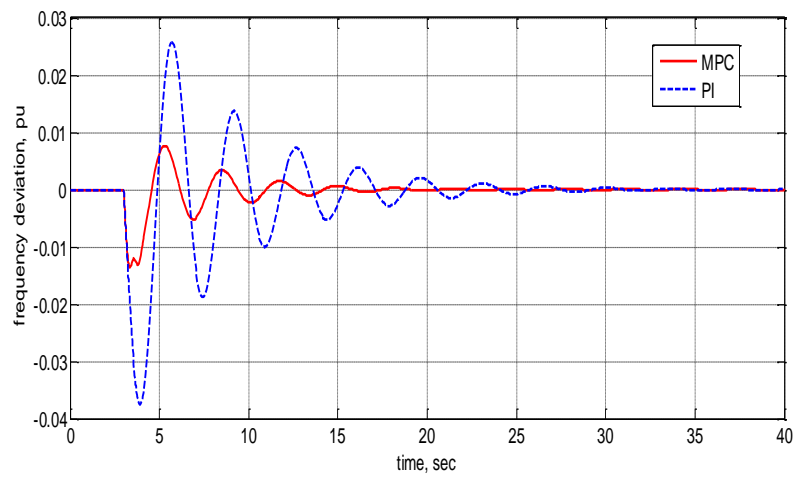

Fig. 5 The frequency response of the studied system due to step change of 0.01 in $\Delta \mathrm{P}_{\mathrm{L}}$.

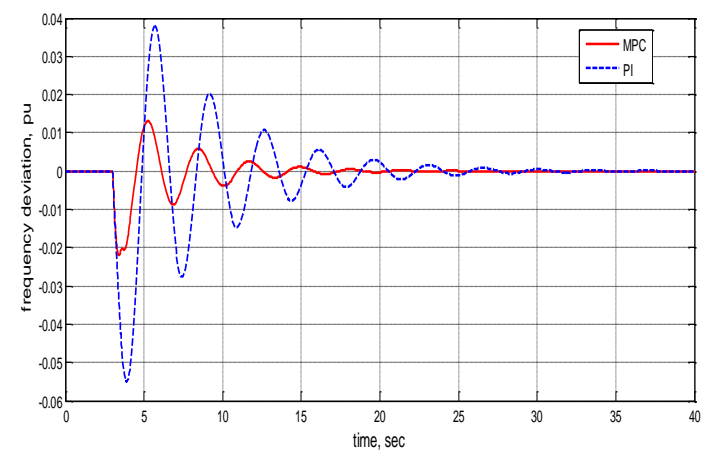

Fig. 6 The frequency response of the studied system due to step change of 0.015 in $\Delta \mathrm{P}_{\mathrm{L}}$.

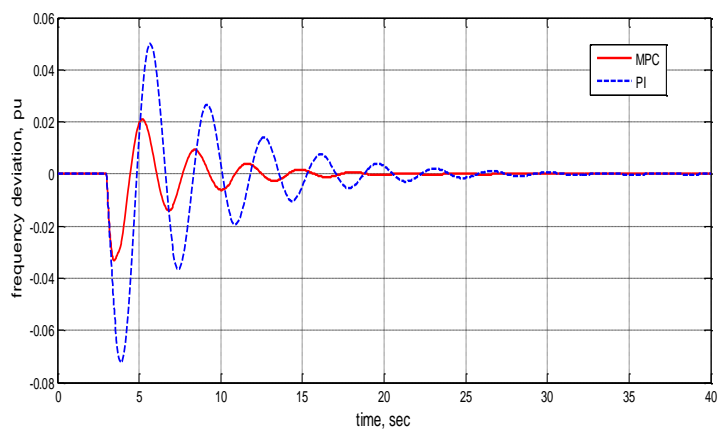

Fig. 7 The frequency response of the studied system due to step change of 0.02 in $\Delta \mathrm{P}_{\mathrm{L}}$.

Figs. 8, 9, 10 and 11 depict the system response due to load changes $0.005 \mathrm{pu}$ and $0.1 \mathrm{pu}$ for the two-area systems. From the simulation results it is clear that the system response with MPC technique is better than with the PI controller, for both area 1,2 and the power deviation in the tie-line $\Delta \mathrm{P}_{\text {tie }}$ The deviation in frequency of the power system in area 1,2 with PI controller has more ripples than with MPC. The system reaches the steady state with MPC very fast compared with PI controller.

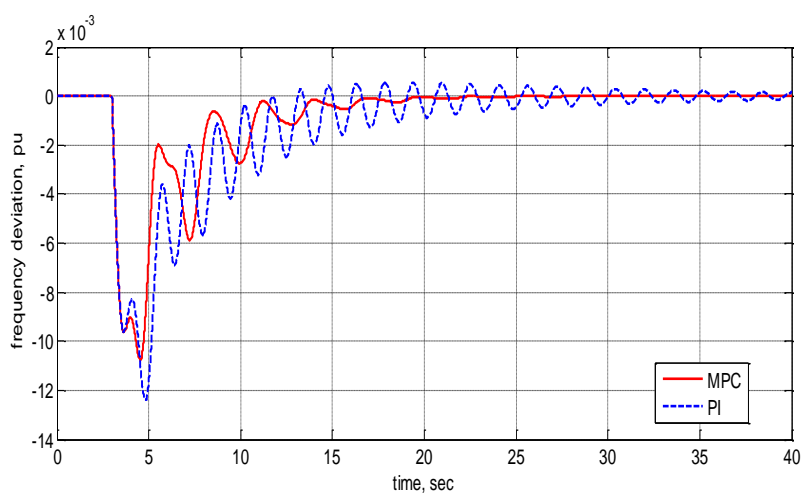

Fig. 8 The frequency response of the studied system for area $\# 1$ due to step change of 0.005 in $\Delta \mathrm{P}_{\mathrm{L}}$.

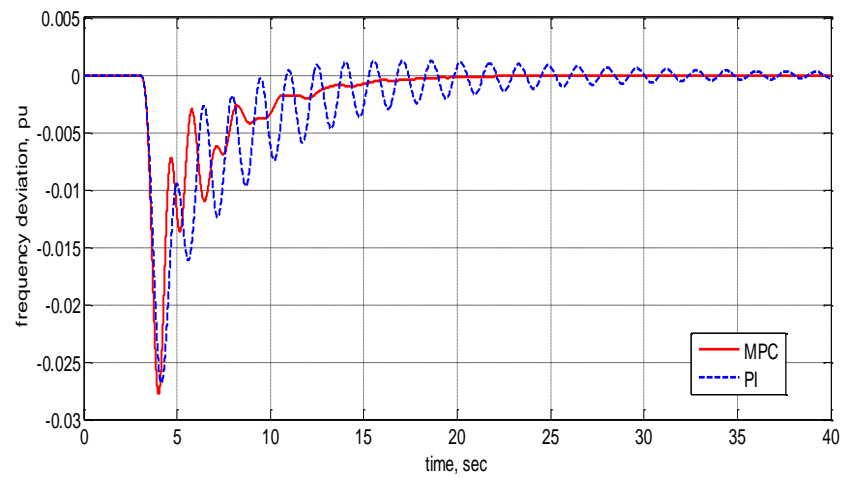

Fig. 9 The frequency response of the studied system for area \#2 due to step change of 0.005 in $\Delta \mathrm{P}_{\mathrm{L}}$.

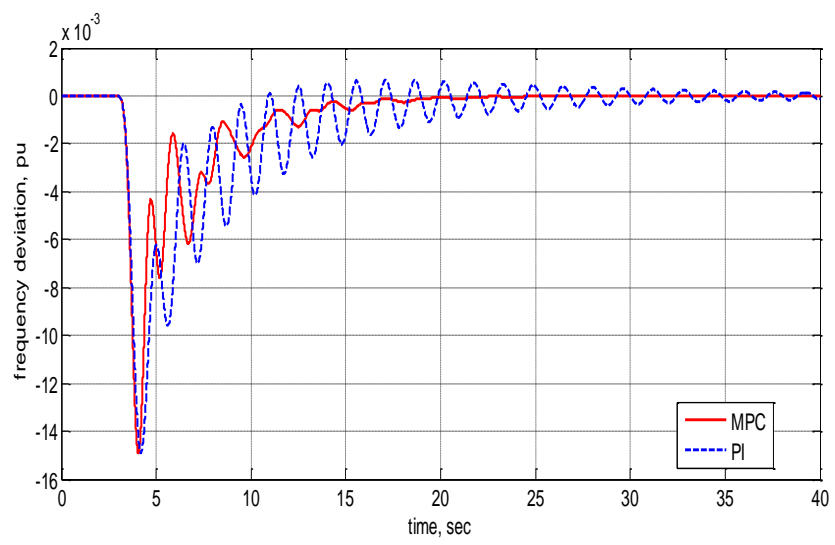

Fig. 10 The frequency response of the studied system for area $\# 1$ due to step change of 0.01 in $\Delta \mathrm{P}_{L}$. 


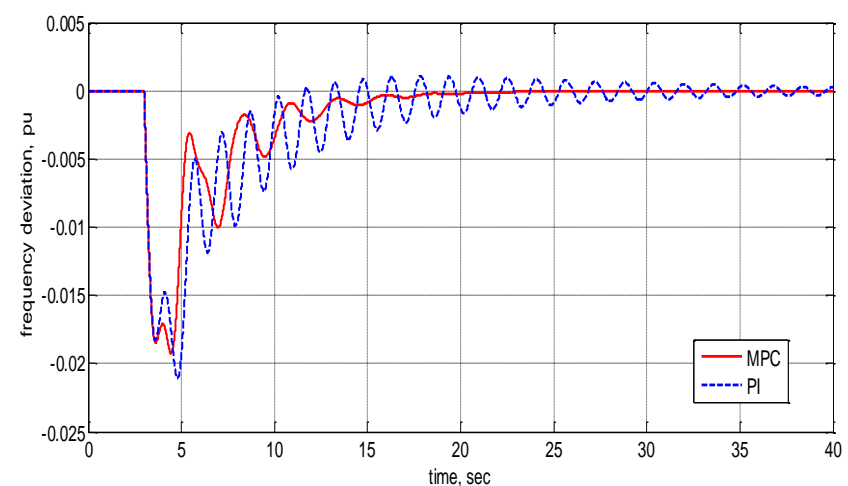

Fig. 11 The frequency response of the studied system for area \#2 due to step change of 0.01 in $\Delta \mathrm{P}_{\mathrm{L}}$.

\section{Conclusions}

Model Predictive control MPC is applied successfully for damping the frequency oscillations of single area system as well as two area system. Different parameters of MPC is implemented with single-area system and two-area system in damping the frequency oscillations very fast with better control quality in compared with PI controller. The predictive control can effectively reject uncontracted load changes and coordinate the transient behavior of a system when contracted load changes occur. The results shows that, the MPC technique gives better stability and more accuracy than the PI controller does for LFC of power system and the only thing that the PI controller outperform the MPC controller is the calculation time.

\section{References}

[1] M. Z. El-sadek, "Power System Control" Book, Mukhtar press, Assiut, Egypt, 2004.

[2] H. Saadat, "Power System Analysis" Book, Kevin Kane, New York, 1997.

[3] A. M. Abdel-Moamen, "Design of New Parametric Controller for Multi-Area Electric Energy System" M.SC.thesis, Faculty of engineering, Assiut University, Egypt, 1998.

[4] Farahani, Mohsen, Soheil Ganjefar, and Mojtaba Alizadeh. "PID controller adjustment using chaotic optimisation algorithm for multi-area load frequency control." IET Control Theory \& Applications 6.13 (2012): 1984-1992.

[5] Toulabi, M. R., M. Shiroei, and A. M. Ranjbar. "Robust analysis and design of power system load frequency control using the Kharitonov's theorem." International Journal of Electrical Power \& Energy Systems 55 (2014): 51-58.

[6] Dhillon, Sukhwinder Singh, J. S. Lather, and S. Marwaha. "Multi objective load frequency control using hybrid bacterial foraging and particle swarm optimized PI controller." International Journal of Electrical Power \& Energy Systems79 (2016): 196-209.

[7] Sekhar, GT Chandra, et al. "Load frequency control of power system under deregulated environment using optimal firefly algorithm." International Journal of Electrical Power \& Energy Systems 74 (2016): 195-211.

[8] Aggarwal, Rajinder P., and F. Robert Bergseth. "Large signal dynamics of load-frequency control systems and their optimization using nonlinear programming: I." IEEE Transactions on Power Apparatus and Systems 2 (1968): $527-$ 532.

[9] Aggarwal, Rajinder P., and F. Robert Bergseth. "Large signal dynamics of load-frequency control systems and their optimization using nonlinear programming: II." IEEE Transactions on Power Apparatus and Systems 2 (1968): 532538.

[10] Dey, Rajeeb, et al. "Hळ load frequency control of interconnected power systems with communication delays." International Journal of Electrical Power \& Energy Systems42.1 (2012): 672-684.

[11] Sun, Yonghui, et al. "Robust Hळ load frequency control of delayed multi-area power system with stochastic disturbances." Neurocomputing 193 (2016): 58-67.

[12] Maher, Rami A., Ismail A. Mohammed, and Ibraheem Kasim Ibraheem. "Polynomial based $\mathrm{H} \infty$ robust governor for load frequency control in steam turbine power systems." International Journal of Electrical Power \& Energy Systems57 (2014): 311-317.

[13] Mi, Yang, et al. "The sliding mode load frequency control for hybrid power system based on disturbance observer." International Journal of Electrical Power \& Energy Systems74 (2016): 446-452.

[14] Kunya, A. B. \& Argin, M. Model predictive load frequency control of multi-area interconnected power system. 2018 IEEE Texas Power Energy Conf. TPEC 2018 2018Febru, 1-6 (2018).

[15] Mohamed, T. H., Bevrani, H., Hassan, A. A. \& Hiyama, T. Decentralized model predictive based load frequency control in an interconnected power system. Energy Convers. Manag. 52, 1208-1214 (2011).

[16] Jayachandran, M., and G. Ravi. "Decentralized model predictive hierarchical control strategy for islanded AC microgrids." Electric Power Systems Research 170 (2019): 92-100.

[17] Papangelis, Lampros, et al. "Decentralized model predictive control of voltage source converters for AC frequency containment." International Journal of Electrical Power \& Energy Systems 98 (2018): 342-349.

[18] Robillart, M., Schalbart, P., Chaplais, F. \& Peuportier, B. Model reduction and model predictive control of energyefficient buildings for electrical heating load shifting. J. Process Control 74, 23-34 (2019).

[19] Mirakhorli, Amin, and Bing Dong. "Model predictive control for building loads connected with a residential distribution grid." Applied energy 230 (2018): 627-642.

[20] Sahaj, Yogesh V. Hote, "PI Controller Based Load Frequency Control Approach for Single-Area Power System Having Communication Delay", IFAC Papers on Line 51-4 (2018) 622-626 
[21] Thomas J, Dumur D, Buisson J, Gueguen H. Model predictive control for hybrid systems under a state partition based MLD approach (SPMLD). In: International conference on informatics in control, automation and robotics ICINCO'04, vol. 3, Set’obal; 2004. p. 78-85.

[22] Richalet J, Rault A, Testud JL, Japon J. Model predictive heuristic control. application to industrial processes. Automatica 1978;14(5):413-28.
[23] W. G. Shi, C. Shao, Z. Y. Sun., " Improved GPC network control algorithm based on AR model time-delay prediction", Control and Decision, Vol. 27, No. 3, pp. 477480, 2012.

[24] Zhong-Da Tian, Shu-Jiang Li, Yan-Hong Wang, HongXia Yu: "Networked Control System Time-Delay Compensation Based on Time-Delay Prediction and Improved Implicit GPC", Algorithms 8, no. 1: 3-18, 2015.

[25] Bevrani H. Robust power system control. New York: Springer; 2009. 